\title{
The Analytical Sciences Digital Library (ASDL)
}

\author{
Cynthia K. Larive
}

Published online: 30 October 2009

(C) The Author(s) 2009. This article is published with open access at Springerlink.com

The Analytical Sciences Digital Library (ASDL) is a collection of electronic resources for teachers, students, and practitioners interested in chemical measurements and instrumentation. The ASDL collection is freely accessible at www. asdlib.org. This project has been funded by the National Science Foundation's National Science Digital Library (NSDL) program. The NSDL (http://nsdl.org/) is an online library for education and research in science technology, engineering and mathematics. All NSDL content, including that in the ASDL, is freely available on the Internet.

The ASDL was launched in 2002 following discussions at regional and national meetings about ways to implement the recommendations embodied in a report from a National Science Foundation (NSF)-funded workshop on "Curricular developments in the analytical sciences" [1]. The analytical sciences include analytical chemistry, and other disciplines in which measurement plays a central role, for example, chemical engineering, public health, forensics, and environmental science. The ASDL provides an annotated collection of electronic resources and serves as a resource for curricular development in the analytical sciences. Materials cataloged in the ASDL are selected for their educational value through a peer-review process.

\section{Role of ASDL editors}

The selection and peer review of ASDL content is guided by experts in the analytical sciences who volunteer as ASDL associate editors. The current ASDL editorial staff is

C. K. Larive $(\square)$

Department of Chemistry, University of California,

Riverside, CA 92521, USA

e-mail: cindy.larive@ucr.edu summarized in Table 1. Every item in the ASDL collection is carefully peer reviewed by at least two experts in the field. In addition, ASDL provides added value for users. Each entry in the collection includes an annotation, or brief description, prepared by the editor along with a judgment about the level of user (beginner, intermediate, expert) for whom the site is most appropriate.

\section{The ASDL portal}

By providing an organizational framework, ASDL content materials can be readily surveyed or searched. A screenshot of the ASDL portal is shown in Fig. 1. The ASDL maintains two collections of peer-reviewed electronic resources: 1 . the web collection, which annotates and catalogs existing electronic resources, and 2. online articles-published through the Journal of the Analytical Sciences Digital Library $(J A S D L)$ - which actively encourages the development of new electronic resources. A wide range of materials can be accessed through the ASDL and the collection is continually evolving. Suggestions of websites for consideration for inclusion in the collection are welcome.

The web collection

ASDL's web collection contains more than 400 electronic resources organized in the following areas:

- Techniques: computations, electrochemistry, instrumentation, mass spectrometry, NMR, separations, spectroscopy, and surface methods

- Applications: application library, bioanalytical, databases, environmental, forensics, materials, nano methods, and quantitative analysis 
Table 1 ASDL editorial staff

ASDL managers ASDL associate editors

Editor-in-chief, Cynthia Larive

(UC Riverside)

Managing director, Theodore Kuwana

(Univ. Kansas)

$J A S D L$ articles editor, Alexander Scheeline

(Univ. Illinois)

Weblink collection editor, David Harvey

(Depauw University)
Sandra Barnes (Alcorn State University)

Sapna Deo (IUPUI)

Dale Karweik (The Ohio State University)

Carol Korzeniewski (Texas Tech University)

William Otto (University of Maine Machias)

Thomas Spudich (U.S. Military Academy)

Philip Voegel (Southern Louisiana University)
Heather Bullen (Northern Kentucky University)

Erin Gross (Creighton University)

Richard Kelly (East Stroudsburg University)

Patricia Mabrouk (Northeastern University)

Richard Saferstein (Widener University)

Dwight Stoll (Gustavus Adolphus College)
- Learning resources: animations, Etexts, exercises, laboratory experiments, lecture materials, tutorials, videos, and virtual labs

- Teaching resources: active learning, assessments, and best practices

Resources in the web collection can be searched by entering a keyword in the search box at the upper right hand corner of the site. Alternatively the collection can be browsed by clicking on the categories listed from the main page. The category of "Techniques" highlights resources that illustrate the fundamental principles underlying various instrumental techniques, the nuts and bolts of how the instruments work, and factors related to their use. Students and faculty looking for material related to a specific instrumental topic often start their search by browsing the category related to that technique. Examples of resources in this category include videos and animations showing

\begin{tabular}{|c|c|c|c|c|c|}
\hline \multicolumn{6}{|c|}{ ASDL Analytical Sciences Digital Library (SF } \\
\hline Home About ASDL & ASDL People & Associate Links & How to Contribute & Site Map & Review System \\
\hline \multicolumn{5}{|c|}{$\begin{array}{l}\text { THE ASDL COLLECTION- The Analytical Sciences Digital Library collects, cataloos, annotates and links peer-reviewed web-based educational resources } \\
\text { and publishes the online journal, JASDL. }\end{array}$} & $\begin{array}{l}\text { Visit our Partners: } \\
\text { The ACS Division of Analytical Chemistry } \\
\text { Ihe Association for Laboratory Automation- } \\
\text { LabAutopedia }\end{array}$ \\
\hline Techniques & Applications & Learning Resources & Teaching Resources & $\underline{\text { JASDL }}$ & \multirow{6}{*}{ 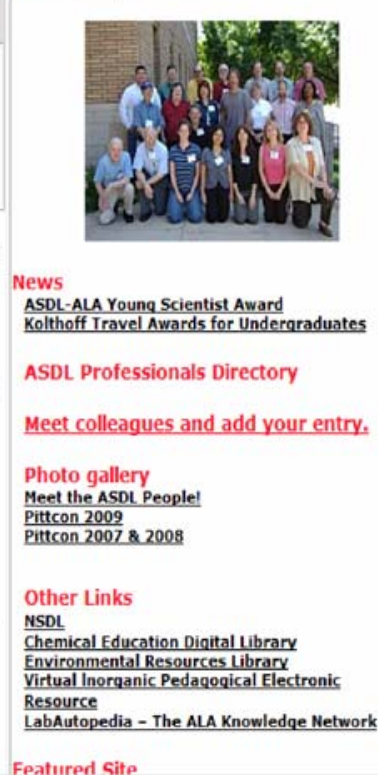 } \\
\hline 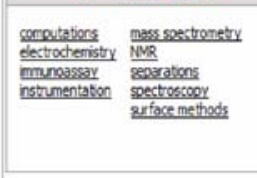 & 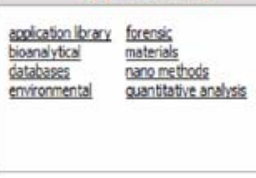 & 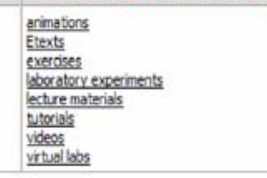 & 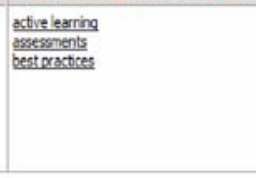 & 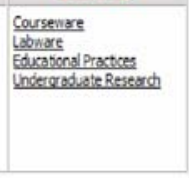 & \\
\hline \multicolumn{5}{|c|}{$\begin{array}{l}\text { JASDL Discover the Journal of the Analytical Sciences Digital Library. JASDL publishes peer-reviewed electronic resources including artices, texts, curriculum modules, } \\
\text { and experiments. }\end{array}$} & \\
\hline courseware & educational pradtices & undereraduate research & & & \\
\hline \multicolumn{5}{|c|}{ 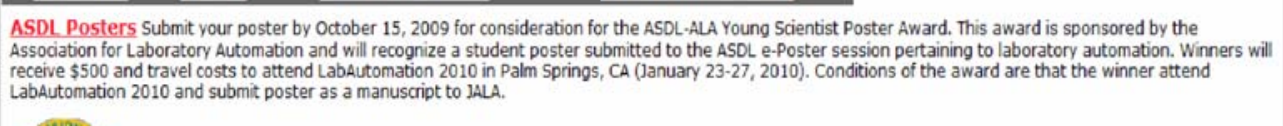 } & \\
\hline \multicolumn{5}{|c|}{$\begin{array}{l}\text { The Analytical Sciences Digital Library is possible thanks to the support of NSF grants DUE } 0121518 \text { to the Universty of Kansas, DUE } 0531941 \text { to the University of Calffornia - } \\
\text { Riverside, and DUE } 0435422 \text { to the University of llinois Urbana-Champaign }\end{array}$} & \\
\hline
\end{tabular}

Fig. 1 A screenshot of the main ASDL portal. Users can search for content by typing keywords into the search box at the upper right hand corner of the page. Alternatively, the electronic resources in the web collection can be browsed by clicking on the categories listed under the headers "Techniques", "Applications", "Learning Resources", or "Teaching Resources". Articles published in JASDL, the ASDL electronic journal, can also be accessed from the main ASDL page 
instrumental components and how they function, and Etexts, tutorials, and lecture slides describing instrumental topics. In addition to cost, Etexts have advantages over the traditional bound format in that they are easier to search and animations, simulations, or videos can be directly incorporated into the textbook as an aid to visual learners. A particularly interesting example of an Etext on "Separation science" by Tom Wenzel, Bates College, supports an inquiry-learning course and includes in-class cooperative learning exercises on chemical equilibria and chromatography [2]. The "Applications" category highlights ways in which various analytical techniques and methods can be used to address problems in areas like bioanalytical chemistry, environmental chemistry, or forensics. The "Learning Resources" category organizes materials by the type of resource, providing faculty access to animations, simulations, and videos to incorporate into their lectures or new laboratory experiments to try. An example of an animated description of an inductively coupled plasma instrument using a CCD detector is among a large collection of animated teaching tools created by Tom Chasteen at Sam Houston State University (Fig. 2) [3]. The "Teaching Resources" category provides inquiry- or problem-based curricular materials, case studies, and examples of the use of inquiry-based learning in teaching analytical science courses. Also in this category are examples of assessment tools and best practices. Because the journal Analytical and Bioanalytical Chemistry makes the content of its "ABC's of Teaching Analytical Science" column freely available, many of these articles are also accessible through the ASDL web collection. Examples include editorials on the use of animations and simulations in teaching [4], a project-based atomic spectroscopy lab to measure lead and arsenic distributions in a contaminated apple orchard [5], and a summary by Peter Griffiths of the curriculum and testing methods for quantitative analysis courses taught in the Western USA [6].

Journal of the Analytical Sciences Digital Library $(J A S D L)$

To provide instructors with an outlet for disseminating original, self-authored electronic resources, the ASDL launched the Journal of the Analytical Sciences Digital Library in 2007. Alex Scheeline, at the University of Illinois at Urbana-Champaign, serves as the JASDL editor. Authors publishing in $J A S D L$ retain the copyright for their materials through a Creative Commons license that allows for the free distribution, use, and modification of the materials provided that proper attribution is given to the original author [7]. Authors are ensured that their materials are available to a broad community of users and will remain accessible through the ASDL, alleviating the need for authors to maintain an independent web site. JASDL publishes peer-reviewed materials in four areas:

- Courseware: materials to enhance lecture, seminar, casestudy, and recitation sections of classroom and virtual courses, including innovative problems, data sets, Etexts, and scenarios

- Labware: innovative laboratory experiments, courses, and approaches

- Educational practices: papers, software, and critical analyses of teaching methods related to analytical pedagogy

- Undergraduate research: a forum for posting experience with and results of undergraduate research

Unlike the web collection, which provides annotated links to electronic resources outside the ASDL portal, $J A S D L$ resources are hosted by the ASDL server. One example of a popular $J A S D L$ courseware resource is an
Fig. 2 Schematic showing multielement analysis by ICP using a CCD [3]

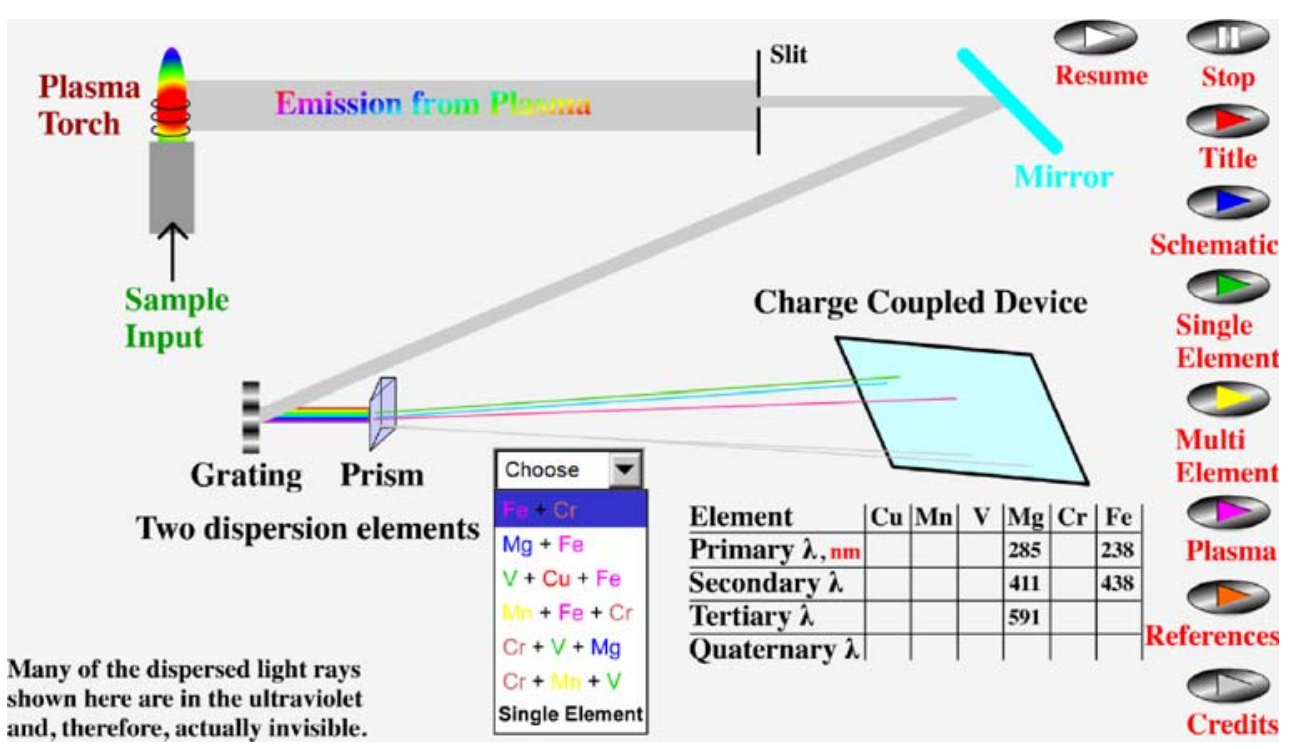


Etext on "Green chemistry" written by Stanley Manahan, University of Missouri [8]. From the JASDL record for this resource, each of the 14 chapters of the "Green chemistry" Etext can be downloaded as pdf files, with the figures available as separate PowerPoint ${ }^{\mathrm{TM}}$ slides. Another JASDL labware resource that aptly illustrates the value of electronic publication is "Micro separations - distance CE", by Lisa Holland et al. at West Virginia University [9]. This article, describing how to assemble an inexpensive, yet reliable capillary electrophoresis apparatus and providing experiments to demonstrate electrodynamically driven separations, was first published in 2005 , with a revised and updated version published nearly a year later.

The development of materials for JASDL has been aided by week-long ASDL-sponsored curriculum development workshops, held each summer since 2006. Examples of $J A S D L$ resources developed during these workshops include "Introduction to signals and noise" [10], "Applied electrochemistry: potentiometry" [11], "Introduction to data analysis" [12], "Introduction to scanning probe microscopy" [13], and "Analytical electrochemistry: a laboratory manual" [14]. A curriculum development workshop for summer 2010 is in the planning stages and faculty interested in participating are encouraged to contact the author for additional information.

Building upon these successful summer workshops, current funding from an NSF Course, Curriculum and Laboratory Improvement grant supports the development of new inquiry-based curricular materials to provide undergraduate instruction in the analytical sciences. Resources on chemical equilibria, separations, quantitative NMR, and organochlorine pesticide analyses using GC-MS are under development in projects led by Thomas Wenzel (Bates College), Alanah Fitch (Loyola University), Heather Bullen (Northern Kentucky University), Rick Kelly (East Stroudsburg University), and Cindy Larive (UC Riverside). Development of inquiry- or problem-based electronic resources with flexibility in the mode of implementation are a high priority for $J A S D L$, and the submission of resources from the analytical sciences community is welcomed.

\section{Building a community of users}

The success of any library-whether physical or digitaldepends upon a community of users that finds value in the resource. The ASDL "Virtual poster session" and "Directory of analytical professionals" facilitate communications between users or between the ASDL and its users:

\section{Virtual poster session}

The ASDL hosts an online virtual poster session, providing students with an opportunity to share the results of their undergraduate or graduate research projects with the broader analytical community, and providing companies and national laboratories with the opportunity to share emerging technologies. Posters are added on a continuous rolling basis with each poster remaining visible on the site for 1 year, after which it is archived and available by searching the ASDL.

\section{Directory of analytical sciences professionals}

This voluntary list, maintained by the ASDL, allows instructors, students, and practitioners of the analytical sciences to share their contact information and research interests as a means of fostering community development and collaboration. Because the directory is a database, it can be used to contact users to update them about new ASDL features. Because the professionals who register in the directory provide a summary of their expertise and research interests, this database can be used by analytical scientists seeking potential collaborators or reviewers. At present there are more than 140 registered users, many of whom have contributed directly to the ASDL through the $J A S D L$ and/or the virtual poster session. The majority of registered users are analytical chemistry faculty members at higher education institutions in the USA; however, as described below the ASDL has an international audience and analytical professionals around the world are invited to contribute their information to the directory.

Statistics on usage of the ASDL

ASDL has become an important resource for faculty, students, and practitioners of analytical science worldwide. During the calendar year 9/11/2008-9/11/2009 ASDL received 20,813 visits with 46,381 page views (on average 2.23 page views per visit). The average user spent $2 \mathrm{~min} 54 \mathrm{~s}$ on the site. Most visitors were from the USA (41\%), followed by India, the UK, Canada, Iran, Australia, Brazil, Malaysia, and Germany. Thirty-seven percent of the visitors reached the site directly by typing www.asdlib.org into their web browser. Fifty-one percent of visitors were referred to ASDL by a search engine while $3 \%$ (486 unique visitors) were referred to ASDL by the website of the ACS Division of Analytical Chemistry, www.analyticalsciences.org).

\section{ASDL partners}

In 2007 the ASDL and the American Chemical Society's Division of Analytical Chemistry (ANYL) formed a partnership in which ANYL provides fiscal assistance in support of the ASDL's basic web operation. The ASDL 
portal can be accessed directly from the ANYL website www.analyticalsciences.org. This partnership significantly expands the potential community of users by making the 10,500 members of the Analytical Division aware of the ASDL. It also helps ensure the long-term sustainability of ASDL's web operation. More recently the Association for Laboratory Automation (ALA) has also partnered ASDL to promote education in the analytical sciences by sponsoring the ASDL-ALA Young Scientist Poster Award, which will support attendance of a student poster author at LabAutomation 2010.

\section{Looking to the future}

Several projects to improve and advance the ASDL are underway. The editorial board is working to improve the ease of browsing the web collection by adding an additional layer of subcategories to the categories under "Techniques", "Applications", and "Learning Resources". David Harvey, Depauw University, has recently obtained additional NSF funding to develop a community site that will be linked to ASDL. This site will allow users of the ASDL to tag resources, post and share teaching materials like lessons and homework problems that use ASDL resources, and sign up for alerts when new ASDL resources have been added to the collection.

ASDL is a dynamic project that relies heavily on contributions from the analytical sciences community. Other organizations can partner with ASDL in our mission to provide high quality educational materials covering all aspects of chemical measurements and instrumentation. Professors provide content for the JASDL, participate as peer reviewers, and volunteer as associate editors. Students are encouraged to submit posters describing their research for the ASDL virtual poster session. Analytical science practitioners can recommend content for consideration for inclusion in ASDL. Finally, everyone interested in analytical science is invited to join the community of users in the ASDL professionals directory.

Acknowledgements We gratefully acknowledge funding for the ASDL from NSF grants DUE 0121518 to the University of Kansas, DUE 0435422 to the University of Illinois Urbana-Champaign, DUE 0531941 and 0817595 to the University of California Riverside, DUE 0816649 to Bates College and DUE 0937751 to Depauw University. CKL especially acknowledges the leadership and continued contributions of Professor Emeritus Ted Kuwana, University of Kansas, to the development and continued evolution of the ASDL project.
Open Access This article is distributed under the terms of the Creative Commons Attribution Noncommercial License which permits any noncommercial use, distribution, and reproduction in any medium, provided the original author(s) and source are credited.

\section{References}

1. Kuwana $\mathrm{T}$ (2001) Curricular developments in the analytical sciences: a report from the workshops. http://www.asdlib.org/ files/curricularDevelopment_report.pdf. Accessed 30 Sept 2009

2. Wenzel TJ (2009) Chem 212 - separation science. http://www. bates.edu/x65385.xml. Accessed 1 Oct 2009

3. Chasteen TG (2009) Inductively coupled plasma spectrometer. http://www.shsu.edu/ chm_tgc/sounds/flashfiles/ICPwCCD.swf. Accessed 1 Oct 2009

4. Larive CK (2008) Anal Bioanal Chem 390:71-75

5. Amarasiriwardena D (2007) Anal Bioanal Chem 388:307-314

6. Griffiths PR (2008) Anal Bioanal Chem 391:875-880

7. Creative Commons (2009) License your work. http://creativecom mons.org/choose/. Accessed 1 Oct 2009

8. Manahan SE (2008) Green chemistry, ASDLID\# 10046. http:// www.asdlib.org/onlineArticles/ecourseware/Manahan/Green Chemistry.php. Accessed 1 Oct 2009

9. Holland LA, White CM, Hansen KM (2005) Micro separations distance CE, ASDLID\# 10031. http://www.asdlib.org/online Articles/elabware/holland_research/distance_ce.htm. Accessed 1 Oct 2009

10. Petrovic S (2008) Introduction to signals and noise - elearning module, ASDLID\#10055. http://www.asdlib.org/onlineArticles/ ecourseware/Petrovic/signals_noise1.htm. Accessed 1 Oct 2009

11. Gross EM, Kelly RS, Cannon DM Jr (2008) Analytical electrochemistry: potentiometry, ASDLID\# 10052. http://www.asdlib. org/onlineArticles/ecourseware/Gross_Potentiometry/potentio metry 1.htm. Accessed 1 Oct 2009

12. Harvey D, Otto W (2007) Introduction to data analysis, ASDLID\# 10042. http://asdlib.org/onlineArticles/ecourseware/Harvey/Data AnalysisASDL.html. Accessed 1 Oct 2009

13. Bullen HA (2007) Introduction to scanning probe microscopy, ASDLID\# 10043. http://asdlib.org/onlineArticles/ecourseware/ Bullen/SPMModule.htm. Accessed 1 Oct 2009

14. Kuwana T (2008) Analyical electrochemistry: a laboratory manual, ASDLID\# 10048. http://www.asdlib.org/onlineArticles/ elabware/kuwanaEC_lab/ec_labmanuall.htm. Accessed 1 Oct 2009

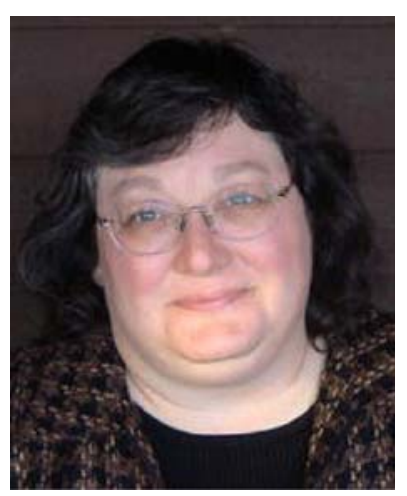

Cynthia Larive is Professor of Analytical Chemistry at the University of California Riverside. She has an active research program involving bioanalytical and environmental analytical applications of NMR spectroscopy (for more information, see http://www.chem. ucr.edu/faculty/larive/larive. $\mathrm{html})$. Dr. Larive is also active in curricular reform and the promotion of undergraduate research. She is editor-in-chief and principal investigator of the Analytical Sciences Digital Library (http://www.asdlib.org). 